\title{
Geochemistry of Clathrate-Derived Methane in Arctic Ocean Waters
}

${ }^{1}$ Scott Elliott, ${ }^{2}$ Matthew Reagan, ${ }^{2}$ George Moridis, ${ }^{3}$ Philip Cameron Smith

${ }^{1}$ COSIM (Climate Ocean Sea Ice Modeling), Los Alamos National Laboratory

${ }^{2}$ Earth Sciences Division, Lawrence Berkeley National Laboratory

${ }^{3}$ Atmosphere Earth and Energy Division, Lawrence Livermore National Laboratory

Abstract. Alterations to the composition of seawater are estimated for microbial oxidation of methane from large polar clathrate destabilizations, which may arise in the coming century. Gas fluxes are taken from porous flow models of warming Arctic sediment. Plume spread parameters are then used to bracket the volume of dilution. Consumption stoichiometries for the marine methanotrophs are based on growth efficiency and elemental/enzyme composition data. The nutritional demand implied by extra $\mathrm{CH}_{4}$ removal is compared with supply in various high latitude water masses. For emissions sized to fit the shelf break, reaction potential begins at one hundred micromolar and falls to order ten a thousand kilometers downstream. Oxygen loss and carbon dioxide production are sufficient respectively to produce hypoxia and acidification in poorly ventilated basins. Nitrogen and the monooxygenase transition metals may be depleted in some locations as well. Deprivation is implied relative to existing ecosystems, along with dispersal of the excess dissolved gas. Physical uncertainties are inherent in the clathrate 
abundance, patch size, outflow buoyancy and mixing rate. Microbial ecology is even less defined but may involve nutrient recycling, metal adsorption and anaerobic oxidizers.

\section{Introduction}

Massive quantities of the greenhouse gas methane are stored beneath the Arctic continental shelf as clathrate hydrates, and the global warming signal is now reaching them (Westbrook et al. 2009). Over contemporary natural seeps, microbial activity tends to oxidize the molecule rapidly (Lamarque, 2008). Emissions driven by upcoming seafloor temperature rise, however, may be unprecedented in scale. Flux zones of dimension tens of kilometers are already under observation (Westbrook et al. 2009). Undersea landslides many times this size have been associated with catastrophic hydrate decomposition in the past (Archer, 2007). The true extent of high latitude clathrates remains unclear, but the eventual appearance of hundred kilometer scale features cannot be precluded. Many polar locations are of appropriate organic content, tectonic history and depth to act as such sources (Gornitz and Fung, 1994; Milkov, 2004).

Marine methanotrophs are likely to be major consumers of any newly emerging methane. They are found ubiquitously through the ocean environment, are notably efficient oxidizers, and bloom aggressively over modern source fields (de Angelis et al. 1993; Hanson and Hanson, 1996). The relevant nutritional requirements can readily be determined by linking conceptual models of physical dilution and metabolic demand. Comparison with the resources dissolved in Arctic seawater then reveals areas of 
geochemical sensitivity. In the present work, preliminary calculations indicate that the clathrate emissions may be capable of stressing regional solute availabilities. Depletions relative to existing biota and expansion of the methane plumes are logical consequences. Several nuances are explored at the discussion level including recycling, particle stripping, and the participation of alternate microbe types.

Future methane fluxes are drawn from multiphase fluid flow simulations of warming, clathrate-rich sediments (Reagan and Moridis, 2008). Water volumes occupied by the gas follow from a knowledge of Arctic current velocities and mixing behaviors (Csanady, 1973; Schlosser et al. 1995). Oxidant and nutrient uptake are computed from stoichiometries for the unique methanotrophic metabolism (Hanson and Hanson, 1996). The supply of reactants for methane consumption is characterized by ship track and climatological data (e.g. HAAO, 2001; Aguilar Islas et al. 2007).

\section{Background}

The polar continental margin is a dominant $\mathrm{CH}_{4}$ reservoir due to its vast area and low temperature (Milkov, 2004; Archer, 2007). Broad shallows exist in the clathrate susceptibility band 300-600 meters depth along all shelves, including those outside the Arctic proper (Jakobsson et al. 2008). The Barents, Kara, East Siberian, Bering and Okhotsk Seas all boast gentle inclines and evidence of methane production (Judd, 2003; Milkov, 2004; Archer, 2007). Under-explored regions which could be added are found in the Canadian Archipelago, Baffin Bay, and along many peripheral fans/sills/rises. Any of 
these locations could support hydrate layers tens of kilometers long at the appropriate depth range. Strong gas losses cannot be excluded for the global warming period (Lamarque, 2008). We thus hypothesize that large flux fields arise. Geochemical effects are then computed in the resulting plumes. As a primary example, rectangles $300 \mathrm{x} 100$ kilometers are aligned lengthwise and tangent along the slope ( $\mathrm{x}$ and y axes; Figure $\mathrm{S} 1)^{1}$.

${ }^{1}$ Auxiliary materials are appended here as they would appear in a GRL document HTML

Ocean overlying the polar sediments exhibits strongly anomalous hydrography (Schlosser et al. 1995). The central Arctic is tightly enclosed by land concentrating its river input, so that freshened mixed layers are maintained. A permanent density gradient lies just below, but it consists of a cold halocline rather than a thermocline. Warm, salty waters of the Atlantic Layer define the lower boundary. This stable Gulf Stream extension penetrates near Spitsbergen and circulates around the upper slope in a cyclonic sense, at depths corresponding with clathrate sensitivity. Excursions into the Barents and other embayments are well known (e.g. Lammers et al. 1995). A significant portion of future methane release will follow such intermediate systems. Flow generally parallels the shelf break, and so also the long axis of our patch. Mixing will either be diffusive toward open waters or restricted in basins (Figure S1 and Freeland et al. 1998). Bottom velocities remain poorly documented, but reviews of pollutant dispersal suggest 1 to $10 \mathrm{~cm} / \mathrm{s}$ as a starting point (Schlosser et al. 1995). 


\section{Dilution Volumes and Concentrations}

As current crosses the near edge of a hypothesized emission zone, methane begins to accumulate in lower layers. Mixing along the $\mathrm{x}$ direction may be ignored because it is self-reinforcing, so that dilution is modeled in one meter slabs. Reagan and Moridis (2008) estimate gas fluxes of $10 \mathrm{~mole} / \mathrm{m}^{2} \mathrm{y}$ in a case study of Arctic sediments perturbed by global change. Their clathrate reservoir supports decades of output, so that extensive downslope evolution is permitted. Maximum fall off must be defined relative to hydrate properties. An upper limit is set by the pressure-temperature curve, and the lower end by total warming of several degrees. Net elevation change is thus capped here at 300 meters (Gornitz and Fung, 1994; Lamarque, 2008). The $1 \mathrm{~cm} / \mathrm{s}$ velocity is taken as a baseline (Schlosser et al. 1995), so that $\mathrm{CH}_{4}$ builds up for one year. For a well developed decomposition, integrated slab input is $1 \mathrm{~m} \times 100 \mathrm{~km} \times 10 \mathrm{~mole} / \mathrm{m}^{2}$ or $10^{6} \mathrm{~mole}$. A simple quantification of downstream dilution suffices for the concentration conversion. Vertical mixing is bracketed on physical grounds, and its horizontal counterpart through Gaussian plume considerations. The volumes obtained have been verified through analytical and numerical modeling as reviewed in the supplements (Figure and Table S1).

Limits on vertical spreading are defined by either outflow buoyancy or encounter with the halocline. The former is often estimated at a few tens of meters (Archer, 2007), while the density barrier lies within a few hundred meters of even the deepest releases. Baseline mixing in the $\mathrm{z}$ direction is thus fixed at 100 meters. Vertical diffusivities are only a few tenths $\mathrm{cm}^{2} / \mathrm{s}$ at high latitudes because the Brunt Vaisala frequency is weak (Gargett, 
1984). Gaussian mean deviation serves as a measure of growth, defined by $\sigma^{2}=2 \mathrm{Kt}$ (Csanady, 1973). For a few years of activity in $z$, the central choice is seen to be conservative. Over flat sea floor surfaces, horizontal dispersion normal to the system can be viewed as an adjustable box, $y=y_{p}+2 \sigma_{y}$ where $p$ signifies patch. The clathrate situation, however, will usually involve a slope. Reflection complicates matters, and the vertical dimension may be dominated by net drop off. These effects tend to compensate one another and our estimates vary only slightly with angle (Figure S1).

Results are presented in Table 1 for a typical Arctic eddy diffusivity $K_{y}=300 \mathrm{~m}^{2} / \mathrm{s}$ (Gargett, 1984; Carmack et al. 1997) and diverse shelf geometries. The dilution volumes range from 1 to $7 \times 10^{7} \mathrm{~m}^{3}\left(1-7 \times 10^{10}\right.$ liter). Methane concentrations fall between 100 and 10 micromolar by this logic, at the patch terminus or an arbitrary scale distance 1000 kilometers. The round figure levels will function here as a set of benchmarks for assessing consumption. They represent potential, reactable substrate because plume microbes will begin dynamic oxidation immediately.

Faster currents will of course acquire less methane from any particular injection. Mean deviation is proportional to the square root of time, so that volumes remain more tightly focused in such cases. Nevertheless, reactant levels will be reduced in swift flowing systems. For example, it should be noted that the only destabilization so far identified is situated directly below the West Spitsbergen current. Bottom velocities there greatly exceed $10 \mathrm{~cm} / \mathrm{s}$ (Westbrook et al. 2009). Gross approximations underlie our choices of both flux and eddy diffusivity. Moreover, the applicability of Gaussian methods may be 
questioned in a complex transport regime (captions Figure and Table S1). The inherent uncertainties, however, exert upward as well as downward influence. The source 10 mole $/ \mathrm{m}^{2} \mathrm{y}$ provides two illustrations of this point. It falls below not only estimates in recent atmospheric budget exercises (Lamaraque, 2008), but also the Spitsbergen measurements (Westbrook et al. 2009). Our derived concentration range is rough but appropriate for present purposes.

\section{Removal Reactions}

A contemporary marine background of $\mathrm{CH}_{4}$ is supported by methanogenesis in sinking particles and a weak sea bed source (Judd, 2003). The consumers in open water are methanotrophs (de Angelis et al. 1993), and our analysis begins by assuming this will continue. Natural concentrations are much less than micromolar even near pock fields and mud volcanos (Lammers et al. 1995). Since the dissolved gases and biolimiting solutes of seawater are present above these levels (Broecker and Peng, 1982; HAAO, 2001; Aguilar Islas et al. 2007), methanotrophy makes little imprint. It is clear from our plume calculations, however, that future Arctic systems will be more intense. The implied resource requirements are now computed. Kinetic issues can be set aside initially. Doubling times are as short as hours over known seeps (LaRock et al. 1994) and $\mathrm{CH}_{4}$ will be Monod saturated over any regional clathrate source. Uptake must be rapid early on. But alternate limits may arise and will relax only as new nutrients are incorporated. 
Methanotrophic metabolism is powered by the simple reaction $\mathrm{CH}_{4}+2 \mathrm{O}_{2}$ yielding $\mathrm{CO}_{2}+$ $2 \mathrm{H}_{2} \mathrm{O}$ (Hanson and Hanson, 1996), and exhibits a typical growth efficiency of tens of percent (del Giorgio and Cole, 1998). Biomass contains the usual complement of proteins so that N/C is of order 1/5 (Lee and Fuhrman, 1987). The dominant form of fixed nitrogen in oxic seawater is $\mathrm{NO}_{3}^{-}$, excepting surface layers where photosynthesis leads to reduced forms. Nitrate is taken as the reference state here. Given the preliminary nature of our calculations, it is reasonable to assign the round values $-1:-2:+1:-0.1$ as a net stoichiometry for removal/production of $\mathrm{CH}_{4}: \mathrm{O}_{2}: \mathrm{CO}_{2}: \mathrm{NO}_{3}$. The approximations are explained through a complete reaction scheme in Figure S2.

The methanotrophic ability to derive energy from $\mathrm{CH}_{4}$ is due to the presence of methane monooxygenase (MMO). Ecological dynamics of this enzyme are intricate, but they determine both transition metal and redox cycling. A brief summary is thus attempted (again see Figure S2). Based on ribulose versus serine anabolism, methane oxidizers are often lumped into broad classes labeled simply I and II (Hanson and Hanson, 1996). The respective MMO forms are membrane bound or free floating in the cytoplasm. Bound oxygenase is copper-containing and the organisms involved emphasize nitrate nutrition, while the free enzyme type relies on iron as a cofactor and can fix $\mathrm{N}_{2}$. Diazotrophy is in turn inhibited by oxygenation. Across the global environment, a general observation is that I and II coexist whenever methane and molecular oxygen are found together.

Clathrate destabilization will thus create vast new volumes of habitat. 
The two classes are fierce competitors (Graham et al. 1993), and circumstances may favor I if nitrate and oxygen are present or II as $\mathrm{O}_{2}$ and copper become scarce. In a massive plume it is possible that I dominates on the outskirts and $\mathrm{Cu}$ availability actually protects a core of iron reserves. But the trace metals may also be depleted in sequence. For preliminary purposes, either element may be considered limiting. Measurements of bacterial $\mathrm{Cu}$ and $\mathrm{Fe}$ composition are exceptionally difficult due to binding with cell/laboratory chelators and surfaces. But methanotrophic demand is demonstrably high. Reported molar ratios for $\mathrm{Cu}$ and $\mathrm{Fe}$ to carbon range from $10^{-4}$ to $10^{-3}$ (Park et al. 1991; Berson and Lidstrom, 1996). Efficiency lowers the net metal:C factor and overall stoichiometry becomes $-1:-2:+1:-0.1:-3 \times 10^{-5}:-3 \times 10^{-5}\left(-3 \times 10^{-4}:-3 \times 10^{-4}\right)$ for $\mathrm{CH}_{4}: \mathrm{O}_{2}: \mathrm{CO}_{2}: \mathrm{NO}_{3}^{-}: \mathrm{Cu}^{2+}: \mathrm{Fe}^{3+}$.

Potential perturbations to the oxidant/nutrient supply follow directly from multiplication with the benchmark methane range. A sampler of Arctic seawater composition is provided for comparison in Table 2, drawn from the survey in Table S2. Barents seafloor background is characterized to underscore the scale of clathrate destabilizations. In some cases minima have been selected, but since locations remain unknown all open water values are relevant. Intermediate layers are perhaps more likely to be affected, but there are signs that ebullition will shift true injections toward the surface (Westbrook et al. 2009). Despite the retreat of summer sea ice, coverage will remain seasonal so that trapping is possible even in a mixed layer. For all requisite Table 2 compounds/elements, the range of demand overlaps availability. From the standpoint of existing organisms and 
ecosystems this translates to resource depletion. By the same token, hydrate-derived plumes and their oxidizers must expand to seek additional nutrition.

Specific geochemical changes implied include hypoxia in poorly ventilated areas such as the Bering and Okhotsk, where oxygenation drops into the tens of micromolar (Freeland et al. 1998). In the $\mathrm{CO}_{2}$ case the alkalinity differential is cited, relative to dissolved inorganic carbon content. Carbon dioxide will enter the standard carbonate equilibria, pushing DIC closer to excess positive charge and driving acidification (Broecker and Peng, 1982; Steinacher et al. 2009). Real thresholds will depend on factors demanding full dynamic modeling. For example, metals will be variable near boreal river outlets where organic particles reach the coast. Detritus can carry adsorbates downward during settling. Marine organic chemistry may act as a switch on the $\mathrm{CH}_{4}$ transport.

\section{Uncertainties and Conclusions}

The reader will appreciate that with biogeochemistry superimposed upon the dilution estimates, even more complexity is introduced. The most likely result at a basin-wide scale may in fact be heterogeneous -different regions will display distinct responses to future methane throughput. Uncertainties have accumulated continually through the discussions and are by now almost too numerous to mention. But the issues are timely and warrant an effort to be inclusive. In this final section, several further unknowns are mentioned which did not arise as the demand versus supply arguments were developed. 
Warming sediments will inject quantities additional to $\mathrm{CH}_{4}$ gas into the Arctic water column. The upper few meters of sea floor harbor communities of anaerobic oxidizers of methane (AOM; Caldwell et al. 2008), which could assist open water methanotrophs as oxygen partial pressures are lowered. The organisms utilize extra- $\mathrm{O}_{2}$ oxidants such as sulfate, and nitrogen fixation is an option. Cofactor needs differ as well, and in fact metals are among the terminal electron acceptors. To the extent that AOM contributes to plume control, geochemical perturbation factors could diverge from Table 2. However, the organisms involved are weak in both the thermodynamic and kinetic senses, and even slight deviations from a sulfidic state can be toxic. Our feeling is that AOM will play mainly into isolated basin situations, by analogy with well known contemporary habitats (Caldwell et a. 2008). Sediments act in general upon the marine background as a source of transition metals to open water (Aguilar Islas et al. 2007). This process would also be accelerated, obviating copper and iron restrictions somewhat.

The aerobic methanotrophs process ammonium and hydrocarbons fortuitously (Hanson and Hanson, 1996). Could substrate degradation be decoupled from growth, perhaps via enzyme exudation? We suspect it would be maladaptive for the microbes to deplete their foodstuff capriciously. However, it has proven difficult to elucidate this point in the existing literature. Will downstream recycling support enhanced conversions of $\mathrm{CH}_{4}$ to $\mathrm{CO}_{2}$ ? This seems more likely, but the rate cannot be estimated. Stronger contemporary seeps along the mid-latitude shelf leave a discernible particulate rain in their wake (de Angelis et al. 1993; LaRock et al. 1994). Global change injections should also display this behavior, and it could well lead to sequestration of $\mathrm{N} / \mathrm{Cu} / \mathrm{Fe}$. Other extensions of the 
nitrogen cycle can be cited. Hypoxification provides the milieu for production of nitrous oxide, an even stronger greenhouse gas than methane (Fuhrman and Capone, 1991). N atoms/oxidation states could be supplied from photosynthetic ecosystems operating above -internal limitation logic need not apply.

In fact the divergent outcomes are all uncertain at multiple physical and biological levels. But they are vital to the assessment of change and feedbacks in a warming Arctic. Renewed laboratory methanotrophy experiments are definitely in order. It is clear, however, that in situ studies must be undertaken in parallel. Although the bubbles/flows identified near Spitsbergen are not yet showing geochemical effects, they merit closer scrutiny and will increase with time (Westbrook et al. 2009). Intentional (engineered) destabilizations could be considered for well mapped clathrates, accompanied by integrated biomonitoring. New information generated feeds naturally into ecodynamics packages for ocean circulation models. Global systems simulation must soon include not only the methanotrophs, but also any competing organisms and the novel ecosystems maintained. Upper trophic levels must be treated, along with recycling and an entirely new class of organic chemistry (dissolved and particulate). Only then will comprehension be achieved for next generation Arctic $\mathrm{CH}_{4}$ discharges.

Acknowledgements. The authors have been supported by the Assistant Secretary for Fossil Energy, Office of Natural Gas and Petroleum Technology, through the National Energy Technology Laboratory, and by IMPACTS/Abrupt Climate Change, for the U.S. Dept. of Energy under Contract Number DE-AC02-05CH11231. 


\section{References}

Aguilar-Islas, A.M., and 6 others, Micro- and macronutrients in the southeastern Bering

Sea; Insight into iron depleted regimes, Prog. Oceanogr. 73, 99-126, 2007.

Archer, D., Methane hydrate stability and anthropogenic climate change, Biogeosciences 4, 521-544, 2007.

Berson, O., and M.E. Lidstrom, Study of copper accumulation by the type I methanotroph Methylomicrobium albus BG8, Env. Sci. Tech. 30, 802-809, 1996.

Broecker, W.S., and T.H. Peng, Tracers in the Sea, Eldigio Press, 1982.

Carmack, E.C. and 10 others, Changes in temperature and tracer distributions: Results from the 1994 Arctic Ocean section, Deep Sea Res. II 8, 1487-1502, 1997.

Caldwell, S. and 5 others, Anaerobic oxidation of methane: Mechanisms, bioenergetics and the ecology of associated microorganisms, Env. Sci. Tech. 42, 6791-6799, 2008. Csanady, G.T., Turbulent Diffusion in the Environment, D. Reidel, Dordrecht, 1973. de Angelis, M.A., M.D. Lilley, E.J. Olson and J.A. Baross, Methane oxidation in deep hydrothermal plumes of the Endeavour segment, Deep Sea Res. 40, 1169-1186, 1993. del Giorgio, P.A., and J.J. Cole, Bacterial growth efficiency in natural aquatic systems, Ann. Rev. Ecol. Systematics, 503-541, 1998.

Freeland, H.J., and 6 others, WOCE section P1W in the Sea of Okhotsk 1. Oceanographic data description, J. Geophys. Res. 103, 15613-15623, 1998.

Fuhrman, J.A., and D.G. Capone, Possible biogeochemical consequences of ocean fertilization, Limnol. Oceanogr. 36, 1951-1959, 1991.

Gargett, A.E., Vertical eddy diffusivity in the ocean, J. Mar. Res. 42, 359-393, 1984. 
Gornitz, V., and I. Fung, Potential distribution of methane hydrates in the world's oceans, Global Biogeochem. Cycles 8, 335-347, 1994.

Graham, D.W., J.A. Chaudhary, R.S. Hanson and R.G. Arnold, Factors affecting competition between type I and II methanotrophs in two-organism, continuous flow reactors, Microbial Eco. 25, 1-17, 1993.

HAAO, Hydrochemical Atlas of the Arctic Ocean, IARC, Fairbanks Alaska, 2001.

Hanson, R., and T. Hanson, Methanotrophic bacteria, Microbiol. Rev. 60, 439-471, 1996. Jakobsson, M., and 8 others. An improved bathymetric portrayal of the Arctic Ocean, Geophys. Res. Lett. 35, GL033520, 2008.

Judd, A.G., The global importance and context of methane escape from the seabed, GeoMar. Lett. 23, 147-154, 2003.

Lamarque, J.F., Estimating the potential for methane clathrate instability in the $1 \% \mathrm{CO}_{2}$ IPCC AR-4 simulations, Geophys. Res. Lett. 35, GL035291, 2008.

Lammers, S., E. Suess and M. Hovland, A large methane plume east of Bear Island -Implications for the marine methane cycle, Geologische Rundschau 84, 59-65, 1995. LaRock, P.A., J.H. Hyun and B.W. Bennison, Bacterioplankton growth and production at the Louisiana hydrocarbon seeps, Geo-Mar. Lett. 14, 104-109, 1994.

Lee, S., and J.A. Fuhrman, Relationships between biovolume and biomass of naturally derived marine bacterioplankton, Appl. Environ. Microbiol. 53, 1298-1303, 1987. Maeda, M., Transport of copper from the Bering Sea to the northwestern North Pacific, J. Oceanogr. Soc. Japan 42, 333-346, 1986

Milkov, A.V., Global estimates of hydrate bound gas in marine sediments: how much is really out there? Earth Sci. Rev. 66, 183-197, 2004. 
Park, S., and 4 others, Batch cultivation of Methylosinus trichosporium OB3b I. Production of soluble methane monooxygenase, Biotech. Bioeng. 38, 423-433, 1991. Reagan, M.T., and G.J. Moridis, Dynamic response of oceanic hydrate deposits to ocean temperature change, J. Geophys. Res. 113, JC004938, 2008.

Schlosser, P., J.H. Swift, D. Lewis and S.L. Pfirman, Role of the large scale Arctic Ocean circulation in the transport of contaminants, Deep Sea Res. II 6, 1341-1367, 1995.

Steinacher, M., F. Joos, T.L. Frolicher, G.K. Plattner and S.C. Doney, Imminent acidification in the Arctic projected with the NCAR global coupled carbon cycleclimate model, Biogeosci. 6, 515-533, 2009.

Westbrook, G.K., and 18 others, Escape of methane gas from the seabed along the West Spitsbergen margin, Geophys. Res. Lett. 36, GL039191, 2009. 
Table 1. Dilution volume estimates for plumes extending downstream relative to the clathrate methane emissions. Level $\left(\mathrm{y}=\mathrm{y}_{\mathrm{p}}+2 \sigma_{\mathrm{y}}\right)$, reflected $\left(\mathrm{y}=\sigma_{\mathrm{y}}, \mathrm{z}=\Delta \mathrm{z}_{\text {floor }}\right)$ and rectangular basin configurations are all presented.

\begin{tabular}{|l|l|l|l|l|l|l|}
\hline & \multicolumn{3}{|l|}{300 kilometers (patch length $\mathrm{x}_{\mathrm{p}}$ ) } & \multicolumn{3}{l}{1000 kilometers (reference distance) } \\
\hline & $\mathrm{y}$ & $\mathrm{z}$ & volume & $\mathrm{y}$ & $\mathrm{z}$ & volume \\
\hline Level & $370 \mathrm{~km}$ & $100 \mathrm{~m}$ & $3.7 \times 10^{7} \mathrm{~m}^{3}$ & $590 \mathrm{~km}$ & $100 \mathrm{~m}$ & $5.9 \times 10^{7} \mathrm{~m}^{3}$ \\
\hline Slope & $135 \mathrm{~km}$ & $300 \mathrm{~m}$ & $4.1 \times 10^{7} \mathrm{~m}^{3}$ & $245 \mathrm{~km}$ & $300 \mathrm{~m}$ & $7.4 \times 10^{7} \mathrm{~m}^{3}$ \\
\hline Trough & $100 \mathrm{~km}$ & $100 \mathrm{~m}$ & $1.0 \times 10^{7} \mathrm{~m}^{3}$ & $100 \mathrm{~km}$ & $100 \mathrm{~m}$ & $1.0 \times 10^{7} \mathrm{~m}^{3}$ \\
\hline & $100 \mathrm{~km}$ & $300 \mathrm{~m}$ & $3.0 \times 10^{7} \mathrm{~m}^{3}$ & $100 \mathrm{~km}$ & $300 \mathrm{~m}$ & $3.0 \times 10^{7} \mathrm{~m}^{3}$ \\
\hline
\end{tabular}


Table 2. Geochemical perturbations due methanotrophic action on the clathrate $\mathrm{CH}_{4}$ diluent, contrasted with resource availability (or the alkalinity to dissolved inorganic carbon difference in the $\mathrm{CO}_{2}$ case). Abbreviations are L95 -Lammers et al. (1995), F98 -Freeland et al. (1998), S09 -Steinacher et al. (2009), HAAO -Hydrochemical Atlas of the Arctic Ocean (2001), M86 -Maeda (1986), AI07 -Aguilar Islas et al. (2007).

\begin{tabular}{|l|l|l|l|l|l|l|}
\hline Alteration & \multicolumn{2}{|c|}{$\Delta \mu \mathrm{M}$} & Compare $(\mu \mathrm{M})$ & Location & Depth & Ref. \\
\hline & Low & High & & & & \\
\hline$\Delta \mathrm{CH}_{4}$ & -10 & -100 & $0.01-0.03$ & Barents Sea & $300 \mathrm{~m}$ & L95 \\
\hline$\Delta \mathrm{O}_{2}$ & -20 & -200 & $30-100$ & Sea of Okhotsk & $300-1000 \mathrm{~m}$ & F98 \\
\hline$\Delta \mathrm{CO}_{2}$ & +10 & +100 & $150(\mathrm{Alk}-\mathrm{DIC})$ & Central basin & Mixed layer & S09 \\
\hline$\Delta \mathrm{NO}_{3}^{-}$ & -1 & -10 & $1-10$ & Beaufort Gyre & $0-100 \mathrm{~m}$ & HAAO \\
\hline$\Delta \mathrm{Cu}^{2+}$ & $-3 \times 10^{-4}$ & -0.03 & $1-3 \times 10^{-3}$ & Bering Sea & $300-1000 \mathrm{~m}$ & M86 \\
\hline$\Delta \mathrm{Fe}^{3+}$ & $-3 \times 10^{-4}$ & -0.03 & $1 \times 10^{-4}-1 \times 10^{-3}$ & Bering Sea & $0-300 \mathrm{~m}$ & AI07 \\
\hline
\end{tabular}




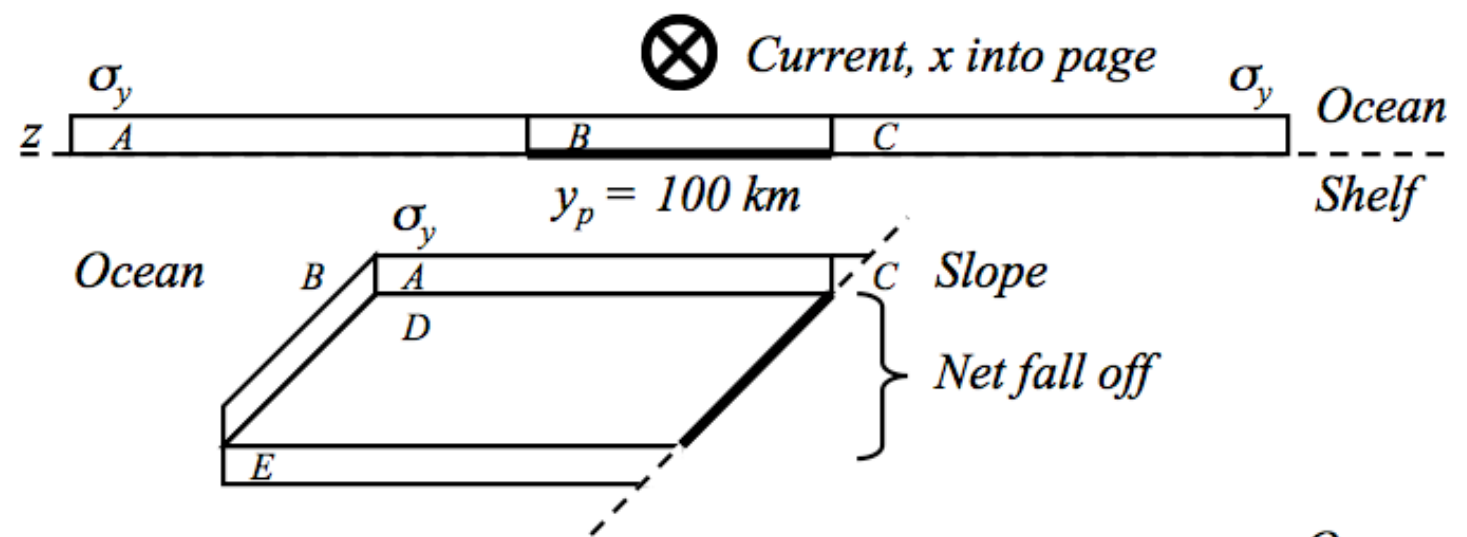

Ocean

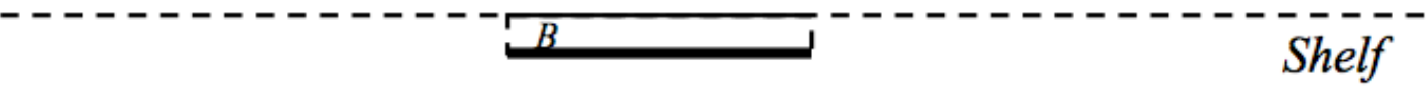

Figure S1. Schematic of geometries developed to provide early estimates of dilution volumes in the Arctic clathrate case. Expanding box models for mixing in the fluid environment are based on mean deviation $\sigma$ as a measure of plume spread in a given direction $\left(\sigma^{2}=2 \mathrm{Kt}\right.$, Csanady, 1973; Bowden, 1975; Sillman et al. 1990). Material actually distributed in a Gaussian manner is conceived of as evenly mixed along a width of several $\sigma$. More deviations may be more inclusive, but we chose 2 as the standard here because it best approximates peak concentrations in a real plume. Our text computes the pictured $\mathrm{A}+\mathrm{B}+\mathrm{C}, \mathrm{D}$ and $\mathrm{B}$ volumes respectively from the flat, slope and trough geometries in order to make the initial assessment presented. Note that D could certainly be augmented with the other areas, but the effect is small and has been ignored in the interest of maintaining clarity. The transition from flat to more complex surface configurations introduces horizontal reflections. These may be dealt with mathematically as mirror image or ghost sources, and analytical solutions for finite emissions can be built up by integration of puffs (Csanady, 1973). Our judgment, however, is that any further development would constitute overkill. Typically the Gaussian boxes are applied as subgrid scale parameterizations for processing on flat surfaces. In air pollution studies, for example, full photochemistry simulations are sometimes conducted in this way (Sillman et al. 1990). The ocean shelf is complex both physically and dynamically, so that the box approach in fact constitutes a mismatch. We offer it here solely as a means for quick evaluation of a new geochemical situation. More complete analytical models of deep and bathymetric marine flow have been reported (review of the foundation literature in Bowden 1975; Smith, 1975; Baringer and Price, 1989) but our strategy from this point will be to move into finely resolved general circulation models. In fact we are beginning to perform full chemistry transport simulations of methane processing in the Parallel Ocean Program or POP, a component of the U.S. Community Climate System Model.

References not in main text bibliography:

Baringer, M.O., and J.F. Price, A simple model of the descending Mediterranean outflow plume, in The Physical Oceanography of Sea Straits, edited by L.J. Pratt, Kluwer, Dordrecht, 1989. 
Bowden, K.F., Oceanic and estuarine mixing problems, in Chemical Oceanography, edited by J.P. Riley and G. Skirrow, 1-41, Academic Press, London, 1975.

Sillman, S., J.A. Logan and S.C. Wofsy, A regional scale model for ozone in the United States with subgrid representation of urban and power plant plumes, J. Geophys. Res. 95, 5731-5748, 1990.

Smith, P.C., A streamtube model for bottom boundary currents in the ocean, Deep-Sea Res. 22, 853-873, 1975. 


\begin{tabular}{|c|c|c|c|}
\hline$\#$ & Reaction & Path & Products \\
\hline 1 & $0.7\left[\mathrm{CH}_{4}+2 \mathrm{O}_{2}\right]$ & $\stackrel{M M O P}{\longrightarrow}$ & $0.7\left[\mathrm{CO}_{2}+2 \mathrm{H}_{2} \mathrm{O}\right]$ \\
\hline 2 & $0.3\left[\mathrm{CH}_{4}+0.2 \mathrm{NO}_{3}^{-}+10^{-4} \mathrm{Cu}^{2+}\right]$ & $\stackrel{\text { MMOP,RUMP }}{\longrightarrow}$ & $0.3[$ Type I $C, N, C u]$ \\
\hline I & $\mathrm{CH}_{4}+1.4 \mathrm{O}_{2}+0.06 \mathrm{NO}_{3}^{-}+3 \times 10^{-5} \mathrm{Cu}^{2+}$ & $\stackrel{\text { Net I }}{\longrightarrow}$ & $0.7 \mathrm{CO}_{2}+0.3[$ Type I $\mathrm{C}, \mathrm{N}, \mathrm{Cu}]$ \\
\hline 3 & $0.7\left[\mathrm{CH}_{4}+2 \mathrm{O}_{2}\right]$ & $\stackrel{M M O S}{\longrightarrow}$ & $0.7\left[\mathrm{CO}_{2}+2 \mathrm{H}_{2} \mathrm{O}\right]$ \\
\hline 4 & $0.3\left[\mathrm{CH}_{4}+0.2 \mathrm{~N}_{f i x}+10^{-4} \mathrm{Fe}^{3+}\right]$ & $\stackrel{\text { MMOs,Ser }}{\longrightarrow}$ & $0.3[$ Type II $\mathrm{C}, \mathrm{N}, \mathrm{Fe}]$ \\
\hline II & $\mathrm{CH}_{4}+1.4 \mathrm{O}_{2}+3 \times 10^{-5} \mathrm{Fe}^{3+}$ & $\stackrel{\text { Net II }}{\longrightarrow}$ & $0.7 \mathrm{CO}_{2}+0.3[$ Type II C,N,Fe] \\
\hline 5 & $\mathrm{CH}_{4}+2 \mathrm{O}_{2}+0.1 \mathrm{NO}_{3}^{-}+3 \times 10^{-5}\left[\mathrm{Cu}^{2+}\right.$ or $\left.\mathrm{Fe}^{3^{+}}\right]$ & $\stackrel{\text { Net I or II }}{\longrightarrow}$ & $\mathrm{CO}_{2}$ \\
\hline 6 & $\mathrm{CH}_{4}+2 \mathrm{O}_{2}+0.1 \mathrm{NO}_{3}^{-}+3 \times 10^{-4}\left[\mathrm{Cu}^{2+}\right.$ or $\left.\mathrm{Fe}^{3+}\right]$ & $\stackrel{\text { Net I or II }}{\longrightarrow}$ & $\mathrm{CO}_{2}$ \\
\hline
\end{tabular}

Figure S2. A simplified conceptual mechanism for the metabolism by aerobic methanotrophs of clathrate-emitted methane in open seawater. Reactions are presented in the order they are likely to follow in nature -type I organisms should dominate until the reagents in 1 and 2 are drawn down. Iron may thus be spared for a time because MMOs processes are suppressed. But methane excess could support the entire sequence. Symbols used are MMOp -the particulate monooxygenase enzyme specific to type I organisms and containing a copper cofactor, MMOs -cytosoluble monooxygenase synthesized by the type II with iron in the active site, RuMP -the ribulose monophosphate anabolism characteristic of type I, Ser -serine anabolism in the type II case, subscript fix for nitrogen fixation. The scheme constitutes a rough unification of overall oxidation and biomass accumulation processes described in the reviews Bedard and Knowles (1989), King (1992), Hanson and Hanson (1996) or Murrell et al. (2000) and represented in experiments/models such as Park et al. (1991), Graham et al. (1993) or Chang and Alvarez-Cohen (1997). Detailed references: Reaction 1 stoichiometry -Hanson and Hanson (1996) and Murrell et al. (2000), Reaction 1 and 2 efficiencies -del Giorgio and Cole (1998) verified in Leak and Dalton (1986a and b) and Murrell et al. (2000), Reaction 2 nitrogen ratio -Lee and Fuhrman (1987), Reaction 2 copper ratio -Fitch et al. (1993), Berson and Lidstrom (1996 and 1997), Reactions 3 and 4 as above but add Park et al. (1991) for the (iron) trace metal factor and Graham et al. (1993) plus Hanson and Hanson (1996) on nitrogen fixation. All values are highly uncertain except for integers inside the brackets, and the dynamics of I versus II competition will be complex. The text thus argues for preliminary demand calculations based on 5, then followed by 6 since enzyme composition is especially problematic. Type I and II biomass production is ignored except in the discussion of downstream effects.

References not in main text bibliography:

Bedard, C., and R. Knowles, Physiology, biochemistry and specific inhibitors of $\mathrm{CH}_{4}$, $\mathrm{NH}_{4}{ }^{+}$and $\mathrm{CO}$ oxidation by methanotrophs and nitrifiers, Microbiol. Rev. 53, 68-84, 1989. 
Berson, O., and M.E. Lidstrom, Cloning and characterization of corA, a gene encoding a copper-repressible polypeptide in the type I methanotroph Methylomicrobium albus BG8, FEMS Microbiol. Lett. 148, 169-174, 1997.

Chang, H.L., and L. Alvarez-Cohen, Two stage methanotrophic bioreactor for the treatment of chlorinated organic wastewater, Wat. Res. 31, 2026-2036, 1997.

Fitch, M.W., and 6 others, Phenotypic characterization of copper resistant mutants of methylosinus trichosporium OB3b, Appl. Environ. Microbiol., 2771-2776, 1993.

King, G., Ecological aspects of methane oxidation, a key determinant of global methane dynamics, Adv. Microbial Ecol. 12, 431-468, 1992.

Leak, D.J., and H. Dalton, Growth yields of methanotrophs 1. Effect of copper on the energetics of methane oxidation, Appl. Microbiol. Biotechnol. 23, 470-476, 1986a.

Leak, D.J., and H. Dalton, Growth yields of methanotrophs 2. A theoretical analysis, Appl. Microbiol. Biotechnol. 23, 477-481, 1986b.

Murrell, J.C., I.R. Macdonald and B. Gilbert, Regulation of expression of methane monooxygenases by copper ions, Trends Microbiol. 8, 221-225, 2000. 
Table S1. Plume widths from models closely related to the present work, evaluated at the 1000 kilometer threshold downstream. Horizontal spread and height in the text are computed in part as additions to initial values, set by the emissions zone shape and buoyancy rise. Several types of analytical and numerical result can be called upon for verification. Instantaneous plane source and plug or square wave solutions to the diffusion equation (Csanady, 1973) give $2 \sigma$ horizontal spreading which is narrower than the expanding dimension employed here. This is because the latter focuses exclusively on edge effects. We have sampled numerical plumes from methane destabilizations now being conducted in the POP model (Parallel Ocean Program), for inert tracer material released at single Arctic bottom cells. Preferred mixing parameterizations are incorporated into POP along with a full treatment of the Coriolis force, which is strong at high latitudes and should compress material against the central shelf/slope. Dispersion calculated in three dimensions confirms the volumes derived here. The present configuration of our general circulation model is identical with a version documented in Elliott (2009), but finer resolution will soon be adopted. Recent intercomparison exercises demonstrate that GCM flow and mixing results are less consistent in the Arctic than the rest of the global ocean (Holloway et al. 2007). The clathrate effluent problem will probably soon demand the attention of multiple groups, simulations and resolutions.

\begin{tabular}{|l|l|l|l|}
\hline Model & Comment & $2 \sigma_{\mathrm{y}}$ & $2 \sigma_{\mathrm{z}}$ \\
\hline Plane Source & & 490 kilometers & 150 meters \\
\hline Plane Source & Reflection & Mirror reductions & Mirror reductions \\
\hline Square Wave & & As above o>initial & As above o>initial \\
\hline Square Wave & Reflection & As above o>initial & As above o>initial \\
\hline POP & Arctic Ocean & $100-300$ kilometers & $<200$ meters \\
\hline & Peripheral seas & Basin-like & Basin-like \\
\hline
\end{tabular}

References not in main text bibliography:

Elliott, S., Dependence of DMS global sea-air flux distribution on transfer velocity and concentration field type, J. Geophys. Res. 114, doi:10.1029/2008JG000710, 2009.

Holloway, G. and 16 others, Water properties and circulation in Arctic Ocean models, J. Geophys. Res. 112, doi: 10.1029/2006JC003642, 2007. 
Table S2. Survey of the chemical composition of seawater at high northern latitudes, with special attention to compounds/elements/relationships affecting or influenced by the Figure S2 equations. In general, data are arranged moving from Pacific to Atlantic and then into the Arctic Ocean proper. Critical patterns underscored in the text are amply apparent. Natural methane concentrations are less than micromolar. The clathrate driven $\mathrm{CH}_{4}$ range established in the text (10-100 micromolar) approaches background concentrations for the major metabolites oxygen and nitrate, for which stoichiometric ratios are near unity. The concentrations are also capable of perturbing $\mathrm{pH}$ through $\mathrm{CO}_{2}$ additions to dissolved carbon. Transition metals are all trace substances in the sea, but with appropriate composition adjustments they also exhibit sensitivity. Copper and iron values quoted refer exclusively to the dissolved total. Symbols -AOU for apparent oxygen utilization, Alk for alkalinity, DIC for dissolved inorganic carbon, GIN for the Greenland-Iceland-Norway region, Si for a silicate correlation study. References are in order of appearance B96 -Bates et al. (1996), W95 -Watanabe et al. (1995), S98 -Suess et al. (1998), L95 -Lammers et al. (1995), DB03 -Damm and Budeus (2003), Andreev and Kusakabe (2001), F98 -Freeland et al. (1998), HAAO -Hydrochemical Atlas of the Arctic Ocean (2001), POP/WOA -results taken from the biogeochemical Parallel Ocean Program version described in Elliott (2009) but validated against the World Ocean Atlas, JA05 -Jutterstrom and Anderson (2005), S09 -Steinacher et al. (2009), AI07 -Aguilar Islas et al. (2007), P93 -Pohl et al. 1993, G97 -Gosselin et al. (1997), M86 -Maeda (1986), H87 -Heggie et al. (1987), M84 -Mart et al. (1984), YW91 -Yeats and Westerlund (1991), T05 -Takata et al. (2005), M99 -Measures (1999).

\begin{tabular}{|l|l|l|l|l|l|}
\hline Substance & $\mu \mathrm{M}$ & Location & Depth & Comment & Reference \\
\hline $\mathrm{CH}_{4}$ & 0.003 & North Pacific & Surface & Supersaturation & B96 \\
\hline & 0.01 & North Pacific & Thermocline & Open water & W95 \\
\hline & $0.01-0.1$ & Aleutians & Slope & Tectonic zone & S98 \\
\hline & $0.03-0.1$ & Bear Island & Shelf & Pock field & L95 \\
\hline & 0.3 & Hakon Mosby & Shelf & Mud volcano & DB03 \\
\hline $\mathrm{O}_{2}$ & $30-100$ & Kamchatka & Intermediate & High AOU & AK01 \\
\hline & 30 & Sea of Okhotsk & $1000 \mathrm{~m}$ & Poorly vented & F98 \\
\hline & 30 & Kuril Basin & $1000 \mathrm{~m}$ & Okhotsk source & F98 \\
\hline & 300 & Nansen Basin & $1000 \mathrm{~m}$ & Saturation & HAAO \\
\hline Alk - DIC & 150 & Bering & $300 \mathrm{~m}$ & Dictates pH & POP/WOA \\
\hline & 200 & $50-70^{\circ}$ north & Surface & & JA05, S09 \\
\hline & 200 & GIN Seas & $300 \mathrm{~m}$ & & POP/WOA \\
\hline & 150 & Arctic Ocean & Surface & & JA05, S09 \\
\hline $\mathrm{NO}_{3}{ }^{-}$ & $<1$ & Bering shelf & Surface & Biolimitation & AI07 \\
\hline & 10 & Bering shelf & $100 \mathrm{~m}$ & & AI07 \\
\hline & 30 & Bering slope & $300 \mathrm{~m}$ & Remineralized & AI07 \\
\hline & $0-3$ & GIN Seas & Surface & Biolimitation & P93 \\
\hline & $1-3$ & Central Arctic & Surface & Ice algal study & G97 \\
\hline $\mathrm{Cu}^{2+}$ & $10^{-3}$ & North Pacific & Surface & Oyashio & M86 \\
\hline & $1-3 \times 10^{-3}$ & Open Bering & $300-1000 \mathrm{~m}$ & & M86 \\
\hline & $<3 \times 10^{-3}$ & Bering shelf & $100 \mathrm{~m}$ & No filtration & H87 \\
\hline
\end{tabular}




\begin{tabular}{|l|l|l|l|l|l|}
\hline & $<10^{-3}$ & Open Bering & $100 \mathrm{~m}$ & No filtration & H87 \\
\hline & $<3 \times 10^{-3}$ & GIN Seas & $100-1000 \mathrm{~m}$ & Voltammetry & M84 \\
\hline & $10^{-3}$ & GIN Seas & Surface & Correlates Si & P93 \\
\hline & $<3 \times 10^{-3}$ & Ellesmere & $100-300 \mathrm{~m}$ & Bottom sources & YW91 \\
\hline $\mathrm{Fe}^{3+}$ & $<3 \times 10^{-4}$ & Central Bering & Surface & Biolimitation & AI07 \\
\hline & $1-3 \times 10^{-4}$ & Central Bering & Surface & & T05 \\
\hline & $10^{-3}$ & Central Bering & $300 \mathrm{~m}$ & Shelf supply & AI07 \\
\hline & $<10^{-3}$ & Central Arctic & Surface & Ice rafts dust & M99 \\
\hline
\end{tabular}

References not in main text bibliography:

Andreev, A.G., and M. Kusakabe, Interdecadal variability in dissolved oxygen in the intermediate water layer of the Western Subarctic Gyre and Kuril Basin (Okhotsk Sea), Geophys. Res. Lett. 28, 2453-2456, 2001.

Bates, T.S., K.C. Kelly, J.E. Johnson and R.H. Gammon, A reevaluation of the open ocean source of methane to the atmosphere, J. Geophys. Res. 101, 6953-6961, 1996.

Damm, E., and G. Budeus, Fate of vent derived methane in seawater above the Hakon Mosby mud volcano (Norwegian Sea), Marine Chem. 82, 1-11, 2003.

Elliott, S., Dependence of DMS global sea-air flux distribution on transfer velocity and concentration field type, J. Geophys. Res. 114, doi:10.1029/2008JG000710, 2009.

Gosselin, M., M. Levasseur, P.A. Wheeler, R.A. Horner and B.C. Booth, New measurements of phytoplankton and ice algal production in the Arctic Ocean, Deep-Sea Res. II 44, 1623-1644, 1997.

Heggie. D., G. Klinkhammer and D. Cullen, Manganese and copper fluxes from continental margin sediments, Geochim. Cosmochim. Acta 51, 1059-1070, 1987.

Jutterstrom, S., and L.G. Anderson, The saturation of calcite and aragonite in the Arctic Ocean, Mar. Chem. 94, 101-110, 2005.

Mart, L., H.W. Nurnberg and D. Dyrssen, Trace metal levels in the eastern Arctic Ocean, Sci. Total Env. 39, 1-14, 1984.

Measures, C.I., The role of entrained sediments in sea ice in the distribution of aluminum and iron in the surface waters of the Arctic Ocean, Mar. Chem. 68, 59-70, 1999.

Pohl, C., G. Kattner and M. Schulz-Baldes, Cadmium, copper, lead and zinc on transects through Arctic and Eastern Atlantic surface and deep waters, J. Mar. Sys. 4, 17-29, 1993.

Suess, E. and 10 others, Fluid venting in the eastern Aleutian subduction zone, J. Geophys. Res. 103, 2597-2614, 1998. 
Takata, H., K. Kuma, S. Iwade and Y. Isoda, Comparative vertical distributions of iron in the Japan Sea, the Bering Sea and the western North Pacific Ocean. J. Geophys. Res. 110, doi:10.1029/2004JC002783, 2005.

Watanabe, S., N. Higashitini, N. Tsurushima and S. Tsunogai, Methane in the western North Pacific, J. Oceanogr. 51, 39-60, 1995.

Yeats, P.A., and S. Westerlund, Trace metal distributions at an Arctic Ocean ice island, Mar. Chem. 33, 261-277, 1991. 